\title{
Cyclic relatively nonexpansive mappings in convex metric spaces
}

\author{
Moosa Gabeleh
}




\title{
CYCLIC RELATIVELY NONEXPANSIVE MAPPINGS IN CONVEX METRIC SPACES
}

\author{
MOOSA GABELEH \\ Received 23 October, 2013
}

\begin{abstract}
A new class of mappings, called generalized orbital cyclic contractions, is introduced and used to study the existence of best proximity points. Existence results of best proximity points for cyclic relatively nonexpansive mappings in the setting of convex metric spaces are also obtained.

2010 Mathematics Subject Classification: 47H10; 47H09

Keywords: best proximity point, fixed point, non-diametral point, cyclic relatively nonexpansive mapping
\end{abstract}

\section{INTRODUCTION}

Let $(X, d)$ be a metric space and let $A$ and $B$ be nonempty subsets of $X$. A mapping $T: A \cup B \rightarrow A \cup B$ is said to be a cyclic mapping provided that $T(A) \subseteq B$ and $T(B) \subseteq A$. A mapping $T: A \cup B \rightarrow A \cup B$ is said to be a cyclic relatively nonexpansive if $T$ is cyclic and $d(T x, T y) \leq d(x, y)$ whenever $x \in A$ and $y \in B$.

If $A \cap B=\varnothing$ then a cyclic mapping cannot have a fixed point, instead it is interesting to study the existence of best proximity points, that is, a point $x \in A \cup B$ such that

$$
d(x, T x)=\operatorname{dist}(A, B):=\inf \{d(x, y):(x, y) \in A \times B\} .
$$

The relevance of best proximity points is that they provide optimal solutions for the problem of best approximation between two sets.

Eldred, Kirk and Veeramani [11] established the existence of a best proximity point for cyclic relatively nonexpansive mappings by using a geometric notion of proximal normal structure in the setting of Banach spaces.

Theorem 1 ([11]). Let $(A, B)$ be a nonempty, weakly compact and convex pair in a Banach space $X$. Let $T: A \cup B \rightarrow A \cup B$ be a cyclic relatively nonexpansive mapping and suppose that $(A, B)$ has the proximal normal structure. Then $T$ has a best proximity point.

This research was in part supported by a grant from IPM (No. 93470047). 
After that in [27], the authors established the existence of best proximity points for cyclic relatively nonexpansive mappings without invoking proximal normal structure.

In [12], the authors proved the following existence, uniqueness and convergence theorem in uniformly convex Banach spaces.

Theorem 2 ([12]). Let $(A, B)$ be a nonempty, closed, and convex pair of subsets of a uniformly convex Banach space $X$ and let $T: A \cup B \rightarrow A \cup B$ be a cyclic contraction mapping, that is, $T$ is cyclic and

$$
\|T x-T y\| \leq \alpha\|x-y\|+(1-\alpha) \operatorname{dist}(A, B),
$$

for every $(x, y) \in A \times B$ and for some $\alpha \in[0,1)$. Then $T$ has a unique best proximity point $x^{*} \in A$ and $\left\{T^{2 n} x\right\}$ converges to $x^{*}$ for every $x \in A$.

Note that the class of cyclic relatively nonexpansive mappings contains the class of cyclic contractions as a subclass. Suzuki et al. [29] generalized Theorem 2 to metric spaces with the property UC (see also [13, 14]). Existence results of best proximity points is an interesting topic in nonlinear analysis which recently attracted the attention of many authors (see for instance $[1-8,10,15,18,20-26,28,31]$ ).

In this article, we introduce a new class of cyclic mappings called generalized cyclic orbital contractions which properly contains the class of cyclic contractions and we study sufficient conditions for the existence of a best proximity point for this class of mappings in convex metric spaces. Moreover, we prove the existence of a best proximity point for cyclic relatively nonexpansive mappings in the setting of convex metric spaces by using a geometric notion of semi-normal structure.

\section{PRELIMINARIES}

In [30], Takahashi introduced the notion of convexity in metric spaces as follows.

Definition 1. Let $(X, d)$ be a metric space and $I:=[0,1]$. A mapping $W: X \times$ $X \times I \rightarrow X$ is said to be a convex structure on $X$ provided that for each $(x, y ; \lambda) \in$ $X \times X \times I$ and $u \in X$,

$$
d(u, \mathcal{W}(x, y ; \lambda)) \leq \lambda d(u, x)+(1-\lambda) d(u, y) .
$$

A metric space $(X, d)$ together with a convex structure $\mathcal{W}$ is called a convex metric space, which is denoted by $(X, d, W)$. A Banach space and each of its convex subsets are convex metric spaces. But a Frechet space is not necessary a convex metric space. The other examples of convex metric spaces which are not imbedded in any Banach space can be founded in [30].

To describe our results, we need some definitions and notations of $[11,30]$.

Definition 2. A subset $K$ of a convex metric space $(X, d, \mathcal{W})$ is said to be a convex set provided that $\mathcal{W}(x, y ; \lambda) \in K$ for all $x, y \in K$ and $\lambda \in I$. 
Proposition 1. Let $(X, d, W)$ be a convex metric space and let $B(x ; r)$ denote the closed ball centered at $x \in X$ with radius $r \geq 0$. Then $B(x ; r)$ is a convex subset of $X$.

Proposition 2. Let $\left\{K_{\alpha}\right\}_{\alpha \in A}$ be a family of convex subsets of $X$, then $\bigcap_{\alpha \in A} K_{\alpha}$ is also a convex subset of $X$.

Definition 3. A convex metric space $(X, d, \mathcal{W})$ is said to have property $(\mathrm{C})$ if every bounded decreasing net of nonempty closed convex subsets of $X$ has a nonempty intersection.

For example every weakly compact convex subset of a Banach space has the property $(\mathrm{C})$.

Let $A$ and $B$ be two nonempty subsets of a convex metric space $(X, d, W)$. We shall say that a pair $(A, B)$ in a convex metric space $(X, d, \mathcal{W})$ satisfies a property if both $A$ and $B$ satisfy that property. For instance, $(A, B)$ is convex if and only if both $A$ and $B$ are convex; $(A, B) \subseteq(C, D) \Leftrightarrow A \subseteq C$, and $B \subseteq D$. We shall also adopt the following notations.

$$
\begin{aligned}
\delta_{x}(A) & :=\sup \{d(x, y): y \in A\} \text { for all } x \in X, \\
\delta(A, B) & :=\sup \{d(x, y): x \in A, y \in B\}, \\
\operatorname{diam}(A) & :=\delta(A, A) .
\end{aligned}
$$

The closed and convex hull of a set $A$ will be denoted by $\overline{\operatorname{cov}}(A)$ and defined as below.

$$
\overline{\operatorname{cov}}(A):=\bigcap\{C: C \text { is a closed and convex subset of } X \text { such that } C \supseteq A\} .
$$

The pair $(x, y) \in A \times B$ is said to be proximal in $(A, B)$ if $d(x, y)=\operatorname{dist}(A, B)$. Moreover, we set

$$
\begin{aligned}
& A_{0}:=\left\{x \in A: d\left(x, y^{\prime}\right)=\operatorname{dist}(A, B), \text { for some } y^{\prime} \in B\right\}, \\
& B_{0}:=\left\{y \in B: d\left(x^{\prime}, y\right)=\operatorname{dist}(A, B), \text { for some } x^{\prime} \in A\right\} .
\end{aligned}
$$

We note that if $(A, B)$ is a nonempty weakly compact and convex pair of subsets of a Banach space $X$ then also is the pair $\left(A_{0}, B_{0}\right)$ and it is easy to see that $\operatorname{dist}(A, B)=$ $\operatorname{dist}\left(A_{0}, B_{0}\right)$.

For a cyclic mapping $T: A \cup B \rightarrow A \cup B$ and $x \in A \cup B$, we define the orbit setting at $x$ by

$$
\mathcal{O}_{T^{2}} x:=\left\{x, T^{2} x, T^{4} x, \ldots, T^{2 n} x, \ldots\right\},
$$

where $T^{2 n} x=T\left(T^{2 n-1} x\right)$ for $n \geq 1$ and $T^{0} x=x$. Note that if $(x, y) \in A \times B$ then $\mathcal{O}_{T^{2}} \subseteq \subseteq A$ and $\mathcal{O}_{T^{2}} y \subseteq B$.

Definition 4. Let $A$ be a nonempty subset in a metric space $(X, d)$. A point $p$ in $A$ is said to be a diametral point if $\delta_{p}(A)=\operatorname{diam}(A)$. 
Definition 5 ([9]). A convex metric space $(X, d, \mathcal{W})$ is said to have normal structure if for each bounded, closed and convex subset $E$ of $X$ which contains at least two points, there exists an element $p \in E$ which is a non-diametral point, that is, $\delta_{p}(E)<\operatorname{diam}(E)$.

Here, we recall the geometric notion of proximal normal structure which was introduced in [11].

Definition 6. A pair $(A, B)$ of subsets of a normed linear space $X$ is said to be a proximal pair if for each $(x, y) \in A \times B$ there exists $\left(x^{\prime}, y^{\prime}\right) \in A \times B$ such that

$$
\left\|x-y^{\prime}\right\|=\left\|x^{\prime}-y\right\|=\operatorname{dist}(A, B) .
$$

Definition 7. A convex pair $\left(K_{1}, K_{2}\right)$ in a Banach space $X$ is said to have proximal normal structure if for any bounded, closed and convex proximal pair $\left(H_{1}, H_{2}\right) \subseteq$ $\left(K_{1}, K_{2}\right)$ for which $\operatorname{dist}\left(H_{1}, H_{2}\right)=\operatorname{dist}\left(K_{1}, K_{2}\right)$ and $\delta\left(H_{1}, H_{2}\right)>\operatorname{dist}\left(H_{1}, H_{2}\right)$, there exits $\left(x_{1}, x_{2}\right) \in H_{1} \times H_{2}$ such that

$$
\delta_{x_{1}}\left(H_{2}\right)<\delta\left(H_{1}, H_{2}\right), \quad \delta_{x_{2}}\left(H_{1}\right)<\delta\left(H_{1}, H_{2}\right) .
$$

It was announced in [11] that every nonempty, bounded, closed and convex pair of subsets of a uniformly convex Banach space $X$ has a proximal normal structure (Proposition 2.1 of [11]).

\section{GENERALIZED CYCLIC ORBITAL CONTRACTIONS}

Motivated by the concept of cyclic contractions and its applications in Theorem 2, we introduce the notion of generalized cyclic orbital contraction and extend the result on cyclic contraction, from a closed convex pair of a uniformly convex Banach space to a bounded closed and convex pair of a convex metric space.

Definition 8. Let $(A, B)$ be a nonempty pair of subsets of a metric space $(X, d)$. A mapping $T: A \cup B \rightarrow A \cup B$ is said to be a generalized cyclic orbital contraction map if $T$ is cyclic on $A \cup B$ and there exists $r \in[0,1)$ such that

$$
d(T x, T y) \leq r \max \left\{\delta_{x}\left(\mathcal{O}_{T^{2} y}\right), \delta_{y}\left(\mathcal{O}_{T^{2} x}\right)\right\}+(1-r) \operatorname{dist}(A, B),
$$

for all $(x, y) \in A \times B$.

Note that every cyclic contraction mapping is a generalized cyclic orbital contraction map. The following example shows that the reverse implication dose not hold.

Example 1. Consider $X:=\mathbb{R}$ with the usual metric. Let $A=B=\left[0, \frac{1}{2}\right]$. Define a mapping $T: A \cup B \rightarrow A \cup B$ by

$$
T x=\left\{\begin{array}{l}
\frac{1}{8} x \text { if } 0 \leq x \leq \frac{1}{4}, \\
0 \text { if } \frac{1}{4}<x \leq \frac{1}{2} .
\end{array}\right.
$$

Then $T$ is generalized cyclic orbital contraction with $r=\frac{7}{8}$. 
Proof. In cases $0 \leq x, y \leq \frac{1}{4}$ and $\frac{1}{4}<x, y \leq \frac{1}{2}$, it is easy to verify that (3.1) holds. Let $0 \leq x \leq \frac{1}{4}$ and $\frac{1}{4}<y \leq \frac{1}{2}$. Then $d(T x, T y)=\frac{1}{8} x$ and $\delta_{x}\left(\mathcal{O}_{T^{2} y}\right)=\sup _{n \geq 0}\left|x-T^{2 n} y\right|=\max \{x, y-x\} \quad \& \quad \delta_{y}\left(\mathcal{O}_{T^{2} x}\right)=\sup _{n \geq 0}\left|y-T^{2 n} x\right|=y$. Thus $\max \left\{\delta_{x}\left(\mathcal{O}_{T^{2} y}\right), \delta_{y}\left(\mathcal{O}_{T^{2} x}\right)\right\}=\max \{x, y-x, x\}=y$. We now have

$$
d(T x, T y)=\frac{1}{8} x \leq \frac{7}{8} y=r \max \left\{\delta_{x}\left(\mathcal{O}_{T^{2} y}\right), \delta_{y}\left(\mathcal{O}_{T^{2} x}\right)\right\} .
$$

that is, $T$ is generalized cyclic orbital contraction. Note that $T$ is not cyclic contraction. Indeed, if $(x, y)=\left(\frac{1}{4}, \frac{26}{100}\right)$ then $d(T x, T y)=\frac{1}{8} \times \frac{1}{4}$. Now, if $T$ is cyclic contraction for some $r \in[0,1)$, then we must have

$$
\frac{1}{32}=d(T x, T y) \leq r d(x, y)=r \times \frac{1}{100},
$$

which is a contradiction.

Let us state our main result of this section.

Theorem 3. Let $(A, B)$ be a nonempty, bounded, closed and convex pair in a convex metric space $(X, d, \mathcal{W})$. Suppose that $T: A \cup B \rightarrow A \cup B$ is a generalized cyclic orbital contraction. If $X$ has the property $(C)$ then $T$ has a best proximity point.

Proof. Let $\Sigma$ denote the set of all nonempty, bounded, closed and convex pairs $(E, F)$ which are subsets of $(A, B)$ and such that $T$ is cyclic on $E \cup F$. Note that $(A, B) \in \Sigma$. Also, $\Sigma$ is partially ordered by revers inclusion, that is $\left(E_{1}, F_{1}\right) \leq$ $\left(E_{2}, F_{2}\right) \Leftrightarrow\left(E_{2}, F_{2}\right) \subseteq\left(E_{1}, F_{1}\right)$. By the fact that $X$ has the property (C), every increasing chain in $\Sigma$ is bounded above. So, by using Zorn's lemma we obtain a maximal element say $(C, D) \in \Sigma$ which is minimal w.r.t inclusion relation. We note that $(\overline{\operatorname{cov}}(T(D)), \overline{\operatorname{cov}}(T(C)))$ is a nonempty, bounded, closed and convex pair in $X$ and $(\overline{\operatorname{cov}}(T(D)), \overline{\operatorname{cov}}(T(C))) \subseteq(C, D)$. Further,

$$
T(\overline{\operatorname{cov}}(T(D))) \subseteq T(C) \subseteq \overline{\operatorname{cov}}(T(C)),
$$

and also,

$$
T(\overline{\operatorname{cov}}(T(C))) \subseteq \overline{\operatorname{cov}}(T(D)),
$$

that is, $T$ is cyclic on $\overline{\operatorname{cov}}(T(D)) \cup \overline{\operatorname{cov}}(T(C))$. It now follows from the minimality of $(C, D)$ that

$$
\overline{\operatorname{cov}}(T(D))=C, \overline{\operatorname{cov}}(T(C))=D .
$$

Let $x \in C$, then $D \subseteq B\left(x ; \delta_{x}(D)\right)$. Now, if $y \in D$ we have

$$
\begin{aligned}
d(T x, T y) & \leq r \max \left\{\delta_{x}\left(\mathcal{O}_{T^{2} y}\right), \delta_{y}\left(\mathcal{O}_{T^{2} x}\right)\right\}+(1-r) \operatorname{dist}(A, B) \\
& \leq r \delta(C, D)+(1-r) \operatorname{dist}(A, B) .
\end{aligned}
$$


Hence, for all $y \in D$ we conclude that

$$
T y \in B(T x ; r \delta(C, D)+(1-r) \operatorname{dist}(A, B)),
$$

and so,

$$
T(D) \subseteq B(T x ; r \delta(C, D)+(1-r) \operatorname{dist}(A, B)) .
$$

Therefore,

$$
C=\overline{\operatorname{cov}}(T(D)) \subseteq B(T x ; r \delta(C, D)+(1-r) \operatorname{dist}(A, B)),
$$

which deduces that

$$
d(z, T x) \leq r \delta(C, D)+(1-r) \operatorname{dist}(A, B), \quad \forall z \in C .
$$

Thus,

$$
\delta_{T x}(C) \leq r \delta(C, D)+(1-r) \operatorname{dist}(A, B) .
$$

Similarly, if $y \in D$ we conclude that

$$
\delta_{T y}(D) \leq r \delta(C, D)+(1-r) \operatorname{dist}(A, B) .
$$

Set

$$
\begin{aligned}
& E:=\left\{x \in C: \delta_{x}(D) \leq r \delta(C, D)+(1-r) \operatorname{dist}(A, B)\right\}, \\
& F:=\left\{y \in D: \delta_{y}(C) \leq r \delta(C, D)+(1-r) \operatorname{dist}(A, B)\right\} .
\end{aligned}
$$

Note that $T(D) \subseteq E$ and $T(C) \subseteq F$. Besides, it is easy to check that

$$
\begin{aligned}
& E=\bigcap_{y \in D} B(y ; r \delta(C, D)+(1-r) \operatorname{dist}(A, B)) \cap C, \\
& F=\bigcap_{x \in C} B(x ; r \delta(C, D)+(1-r) \operatorname{dist}(A, B)) \cap D .
\end{aligned}
$$

Furthermore, if $x \in E$ then by (3.2), $T x \in F$, i.e. $T(E) \subseteq F$ and also by the relation (3.3) $T(F) \subseteq E$, that is, $T$ is cyclic on $E \cup F$. Again, by the minimality of $(C, D)$ we obtain $E=C$ and $F=D$. So, we conclude that

$$
\delta_{x}(D) \leq r \delta(C, D)+(1-r) \operatorname{dist}(A, B), \quad \forall x \in C .
$$

Hence,

$$
\delta(C, D)=\operatorname{dist}(A, B) .
$$

Now, for each pair $\left(x^{*}, y^{*}\right) \in C \times D$ we must have

$$
d\left(x^{*}, T x^{*}\right)=d\left(T y^{*}, y^{*}\right)=\operatorname{dist}(A, B) .
$$

This completes the proof.

The following corollary ensures the existence and uniqueness of a best proximity point in the setting of strictly convex Banach spaces.

Corollary 1. Let $(A, B)$ be a nonempty, bounded, closed and convex pair in a reflexive and strictly convex Banach space $X$. Suppose that $T: A \cup B \rightarrow A \cup B$ is a generalized cyclic orbital contraction. Then $T$ has a unique best proximity point. 
Proof. It now follows from Theorem 3 that there exists a pair $\left(x^{*}, y^{*}\right) \in A \times B$ such that $\left\|x^{*}-T x^{*}\right\|=\left\|T y^{*}-y^{*}\right\|=\operatorname{dist}(A, B)$. The uniqueness of the best proximity point of $T$ follows from the strictly convexity of the Banach space. Indeed, if $\left(u^{*}, v^{*}\right) \in A \times B$ be such that $\left\|u^{*}-T u^{*}\right\|=\left\|T v^{*}-v^{*}\right\|=\operatorname{dist}(A, B)$ then

$$
\begin{aligned}
\operatorname{dist}(A, B) & \leq\left\|\frac{x^{*}+u^{*}}{2}-\frac{T x^{*}+T u^{*}}{2}\right\|=\left\|\frac{x^{*}-T x^{*}}{2}+\frac{u^{*}-T u^{*}}{2}\right\| \\
& <\frac{1}{2}\left(\left\|x^{*}-T x^{*}\right\|+\left\|u^{*}-T u^{*}\right\|\right)=\operatorname{dist}(A, B),
\end{aligned}
$$

which is a contradiction, that is $x^{*}=u^{*}$. Equivalently, we can see that $y^{*}=v^{*}$.

\section{CYCLIC RELATIVELY NONEXPANSIVE MAPPINGS}

In this section we study the existence of a best proximity point for cyclic relatively nonexpansive mappings in the setting of convex metric spaces. For this purpose, we recall a geometric notion of semi-normal structure which was introduced by the current author in [16].

Definition 9 ([16]). A convex pair $\left(K_{1}, K_{2}\right)$ in a convex metric space $(X, d, \mathcal{W})$ is said to have semi normal structure if for any bounded, closed and convex pair $\left(H_{1}, H_{2}\right) \subseteq\left(K_{1}, K_{2}\right)$ for which $\delta\left(H_{1}, H_{2}\right)>\operatorname{dist}\left(H_{1}, H_{2}\right)$, there exits $\left(x_{1}, x_{2}\right) \in$ $H_{1} \times H_{2}$ such that

$$
d\left(x_{1}, x_{2}\right)=\operatorname{dist}\left(K_{1}, K_{2}\right) \quad \& \quad \max \left\{\delta_{x_{1}}\left(H_{2}\right), \delta_{x_{2}}\left(H_{1}\right)\right\}<\delta\left(H_{1}, H_{2}\right) .
$$

We note that if in the above definition $K_{1}=K_{2}$, then $\left(K_{1}, K_{2}\right)$ has semi normal structure if the set $K_{1}$ has normal structure in the sense of Brodskil and Milman ([9]).

In [30], Takahashi extended Kirk's fixed point theorem ([19]) to convex metric spaces as follows.

Theorem 4. Suppose that $(X, d, W)$ is a convex metric space such that $X$ has the property $(C)$. Let $K$ be a nonempty, bounded, closed and convex subset of $X$ with normal structure. If $T: K \rightarrow K$ is a nonexpansive mapping, then $T$ has a fixed point.

Definition 10 ([17]). Let $(A, B)$ be a nonempty pair of subsets of a metric space $(X, d)$. We say that the pair $(A, B)$ is proximal compactness provided that every net $\left(\left\{x_{\alpha}\right\},\left\{y_{\alpha}\right\}\right)$ of $A \times B$ satisfying the condition that $d\left(x_{\alpha}, y_{\alpha}\right) \rightarrow \operatorname{dist}(A, B)$, has a convergent subnet in $A \times B$.

It is clear that if $(A, B)$ is a compact pair in a metric space $(X, d)$, then $(A, B)$ is proximal compactness. Next, we shall prove our main result of this section.

Theorem 5. Let $(A, B)$ be a nonempty, bounded, closed and convex pair in a convex metric space $(X, d, W)$ such that $A_{0}$ is nonempty and $(A, B)$ is proximal compactness. Suppose that $T: A \cup B \rightarrow A \cup B$ is a cyclic relatively nonexpansive mapping. If $(A, B)$ has the semi-normal structure and $X$ has the property $(C)$, then $T$ has a best proximity point. 
Proof. Let $\mathcal{F}$ denote the set of all nonempty, closed and convex pairs $(E, F)$ which are subsets of $(A, B)$ and such that $T$ is cyclic on $E \cup F$ and $d(x, y)=\operatorname{dist}(A, B)$ for some $(x, y) \in E \times F$. Note that $(A, B) \in \mathscr{F}$ by the fact that $A_{0}$ is nonempty. Also, $\mathcal{F}$ is partially ordered by revers inclusion. Assume that $\left\{\left(E_{\alpha}, F_{\alpha}\right)\right\}_{\alpha}$ is a descending chain in $\mathscr{F}$. Set $E:=\bigcap E_{\alpha}$ and $F:=\bigcap F_{\alpha}$. Since $X$ has the property (C), we conclude that $(E, F)$ is nonempty and also is a closed pair. Also, by Proposition 2, $(E, F)$ is a convex pair. Moreover,

$$
T(E)=T\left(\bigcap E_{\alpha}\right) \subseteq \bigcap T\left(E_{\alpha}\right) \subseteq \bigcap F_{\alpha}=F .
$$

Similarly, we can see that $T(F) \subseteq E$, that is, $T$ is cyclic on $E \cup F$. Now, let $\left(x_{\alpha}, y_{\alpha}\right) \in E_{\alpha} \times F_{\alpha}$ be such that $d\left(x_{\alpha}, y_{\alpha}\right)=\operatorname{dist}(A, B)$. Since $(A, B)$ is proximal compactness, $\left(x_{\alpha}, y_{\alpha}\right)$ has a convergent subsequence say $\left(x_{\alpha_{i}}, y_{\alpha_{i}}\right)$ such that $x_{\alpha_{i}} \rightarrow x \in A$ and $y_{\alpha_{i}} \rightarrow y \in B$. Thus

$$
d(x, y)=\lim _{i} d\left(x_{\alpha_{i}}, y_{\alpha_{i}}\right)=\operatorname{dist}(A, B) .
$$

Therefore, there exists an element $(x, y) \in E \times F$ such that $d(x, y)=\operatorname{dist}(A, B)$. Hence, every increasing chain in $\mathscr{F}$ is bounded above w.r.t revers inclusion relation. Then by using Zorn's Lemma we can get a minimal element say $\left(K_{1}, K_{2}\right)$. Let $(p, q) \in K_{1} \times K_{2}$ be such that $d(p, q)=\operatorname{dist}(A, B)$. If $\delta\left(K_{1}, K_{2}\right)=\operatorname{dist}\left(K_{1}, K_{2}\right)$, then for each $(x, y) \in K_{1} \times K_{2}$ we have

$$
d(x, T x)=d(T y, y)=\operatorname{dist}(A, B),
$$

and we are finished. Thus we assume that $\delta\left(K_{1}, K_{2}\right)>\operatorname{dist}\left(K_{1}, K_{2}\right)$. By a similar argument of Theorem 3, we conclude that $\left(\overline{\operatorname{cov}}\left(T\left(K_{2}\right)\right), \overline{c o v}\left(T\left(K_{1}\right)\right)\right) \subseteq\left(K_{1}, K_{2}\right)$ is a nonempty, closed and convex pair such that $T$ is cyclic on $\overline{\operatorname{cov}}\left(T\left(K_{2}\right)\right) \cup \overline{\operatorname{cov}}\left(T\left(K_{1}\right)\right)$. On the other hand,

$$
\operatorname{dist}\left(\overline{\operatorname{cov}}\left(T\left(K_{2}\right)\right), \overline{\operatorname{cov}}\left(T\left(K_{1}\right)\right)\right) \leq d(T q, T p) \leq d(p, q)=\operatorname{dist}(A, B),
$$

and so, $\left(\overline{\operatorname{cov}}\left(T\left(K_{2}\right)\right), \overline{\operatorname{cov}}\left(T\left(K_{1}\right)\right) \in \mathcal{F}\right.$. It now follows from the minimality of $\left(K_{1}, K_{2}\right)$ that $\overline{\operatorname{cov}}\left(T\left(K_{2}\right)\right)=K_{1}$ and $\overline{\operatorname{cov}}\left(T\left(K_{1}\right)\right)=K_{2}$. Since $(A, B)$ has the semi-normal structure, there exists a pair $\left(x^{*}, y^{*}\right) \in K_{1} \times K_{2}$ such that $d\left(x^{*}, y^{*}\right)=$ $\operatorname{dist}\left(K_{1}, K_{2}\right)(=\operatorname{dist}(A, B))$ and if we set

$$
r_{1}:=\delta_{x^{*}}\left(K_{2}\right), \quad r_{2}:=\delta_{y^{*}}\left(K_{1}\right) \quad \text { and } \quad r:=\max \left\{r_{1}, r_{2}\right\},
$$

then $r<\delta\left(K_{1}, K_{2}\right)$. Suppose that

$$
C_{r}\left(K_{2}\right):=K_{1} \bigcap\left(\cap_{x \in K_{2}} B(x ; r)\right) \quad \& \quad C_{r}\left(K_{1}\right):=K_{2} \bigcap\left(\cap_{x \in K_{1}} B(x ; r)\right) .
$$

Propositions 1 and 2, imply that $\left(C_{r}\left(K_{2}\right), C_{r}\left(K_{1}\right)\right)$ is a nonempty, closed and convex pair in $X$. Furthermore, $\left(x^{*}, y^{*}\right) \in C_{r}\left(K_{2}\right) \times C_{r}\left(K_{1}\right)$. We now claim that $T$ is cyclic on $C_{r}\left(K_{2}\right) \cup C_{r}\left(K_{1}\right)$. Let $u \in C_{r}\left(K_{2}\right)$. We must prove that $T u \in C_{r}\left(K_{1}\right)$, or $K_{1} \subseteq B(T u ; r)$. Since $T$ is cyclic relatively nonexpansive,

$$
d(T v, T u) \leq d(u, v) \leq r, \quad \forall v \in K_{2} .
$$


So, $T v \in B(T u ; r)$ for all $v \in K_{2}$ which implies that

$$
K_{1}=\overline{\operatorname{cov}}\left(T\left(K_{2}\right)\right) \subseteq B(T u ; r) .
$$

This deduces that $T u \in C_{r}\left(K_{1}\right)$, that is, $T\left(C_{r}\left(K_{2}\right)\right) \subseteq C_{r}\left(K_{1}\right)$. Similarly, we can see that $T\left(C_{r}\left(K_{1}\right)\right) \subseteq C_{r}\left(K_{2}\right)$. Thus $T$ is cyclic on $C_{r}\left(K_{2}\right) \cup C_{r}\left(K_{1}\right)$. The minimality of $\left(K_{1}, K_{2}\right)$ concludes that

$$
C_{r}\left(K_{1}\right)=K_{2} \quad \& \quad C_{r}\left(K_{2}\right)=K_{1} .
$$

Hence, $K_{2} \subseteq \bigcap_{x \in K_{1}} B(x ; r)$. Therefore, for each $y \in K_{2}$ we have $\delta_{y}\left(K_{1}\right) \leq r$ and so,

$$
\delta\left(K_{1}, K_{2}\right)=\sup _{y \in K_{2}} \delta_{y}\left(K_{1}\right) \leq r,
$$

which is a contradiction. This completes the proof.

The following result is another version of Theorem 5 in the setting of reflexive Banach spaces.

Theorem 6. Let $(A, B)$ be a nonempty, bounded, closed and convex pair in a reflexive Banach space $X$. Suppose that $T: A \cup B \rightarrow A \cup B$ is a cyclic relatively nonexpansive mapping. If $(A, B)$ has the semi-normal structure, then $T$ has a best proximity point.

Proof. At first, we note that $\left(A_{0}, B_{0}\right)$ is a nonempty pair in $X$. Indeed, if $\left\{\left(x_{n}, y_{n}\right)\right\}$ is a sequence in $A \times B$ such that $\left\|x_{n}-y_{n}\right\| \rightarrow \operatorname{dist}(A, B)$, then by the fact that $(A, B)$ is a bounded, closed and convex pair in a reflexive Banach space $X$, the sequence $\left\{\left(x_{n}, y_{n}\right)\right\}$ has a weakly convergent subsequence say $\left\{\left(x_{n_{k}}, y_{n_{k}}\right)\right\}$ such that $x_{n_{k}} \rightarrow$ $x \in A$ and $y_{n_{k}} \rightarrow y \in B$, where " $\rightarrow$ " denotes the weakly convergence. But, according to a well-known fact in basic functional analysis, we have

$$
\operatorname{dist}(A, B) \leq\|x-y\| \leq \liminf _{k \rightarrow \infty}\left\|x_{n_{k}}-y_{n_{k}}\right\|=\operatorname{dist}(A, B),
$$

which implies that $\left(A_{0}, B_{0}\right)$ is nonempty. Now, let $\mathcal{F}$ be the collection of all nonempty, closed and convex pairs $(E, F)$ which are subsets of $(A, B)$ and such that $T$ is cyclic on $E \cup F$ and $\|x-y\|=\operatorname{dist}(A, B)$ for some $(x, y) \in E \times F$. It is interesting to note that $\left(A_{0}, B_{0}\right) \in \mathcal{F}$. In fact, it is easy to verify that the pair $\left(A_{0}, B_{0}\right)$ is closed and convex. Also, if $x \in A_{0}$, then there exists $y \in B_{0}$ such that $\|x-y\|=\operatorname{dist}(A, B)$. Since $T$ is cyclic relatively nonexpansive,

$$
\operatorname{dist}(A, B) \leq\|T x-T y\| \leq\|x-y\|=\operatorname{dist}(A, B),
$$

which implies that $T\left(A_{0}\right) \subseteq B_{0}$. Similarly, we can see that $T\left(B_{0}\right) \subseteq A_{0}$, that is, $T$ is cyclic on $A_{0} \cup B_{0}$. Now, if $\left\{\left(E_{\alpha}, F_{\alpha}\right)\right\}_{\alpha}$ is a descending chain in $\mathcal{F}$ and we put $E:=\bigcap E_{\alpha}$ and $F:=\bigcap F_{\alpha}$, then by the reflexivity of the Banach space $X$, $(E, F)$ is nonempty. Moreover, the pair $(E, F)$ is closed and convex and we can see that $T$ is cyclic on $E \cup F$. Further, if $\left\{\left(x_{\alpha}, y_{\alpha}\right)\right\}$ is a net in $E_{\alpha} \times F_{\alpha}$ such that $\left\|x_{\alpha}-y_{\alpha}\right\|=\operatorname{dist}(A, B)$, then by the fact that $X$ is a reflexive Banach space, there 
exists a subnet $\left\{\left(x_{\alpha_{i}}, y_{\alpha_{i}}\right)\right\}$ such that $x_{\alpha_{i}} \rightarrow x \in E$ and $y_{\alpha_{i}} \rightarrow y \in F$. Thus we must have

$$
\operatorname{dist}(E, F) \leq\|x-y\|=\operatorname{dist}(A, B) .
$$

Hence, $(E, F) \in \mathscr{F}$. It now follows from the Zorn's Lemma that $\mathcal{F}$ has a minimal element say $\left(K_{1}, K_{2}\right)$. Similar argument of Theorem 5, deduces that each point $\left(x^{*}, y^{*}\right) \in K_{1} \times K_{2}$ is a best proximal point of $T$.

Corollary 2. Let $(A, B)$ be a nonempty, weakly compact and convex pair in a Banach space $X$. Suppose that $T: A \cup B \rightarrow A \cup B$ is a cyclic relatively nonexpansive mapping. If $(A, B)$ has the semi-normal structure, then $T$ has a best proximity point.

Corollary 3. Let A be a nonempty, bounded, closed and convex subset of a reflexive Banach space $X$. Suppose that $T: A \rightarrow A$ is a nonexpansive mapping. If $X$ has the normal structure, then $T$ has a fixed point.

The following best proximity point result is valid in uniformly convex Banach spaces.

Theorem 7 ([11]). Let $(A, B)$ be a nonempty, bounded, closed and convex pair in a uniformly convex Banach space $X$. Suppose that $T: A \cup B \rightarrow A \cup B$ is a cyclic relatively nonexpansive mapping. Then $T$ has a best proximity point.

Proof. By a similar manner of Theorem 6, there exists a minimal, closed and convex pair $\left(K_{1}, K_{2}\right) \subseteq(A, B)$ which is $T$-invariant and such that $\operatorname{dist}\left(K_{1}, K_{2}\right)=$ $\operatorname{dist}(A, B)$. Note that minimality of $\left(K_{1}, K_{2}\right)$ implies that $\left(K_{1}, K_{2}\right)$ is a proximal pair. If $\delta\left(K_{1}, K_{2}\right)=\operatorname{dist}\left(K_{1}, K_{2}\right)$, then $T$ has a best proximity point and we are finished. So, we assume that $\delta\left(K_{1}, K_{2}\right)>\operatorname{dist}\left(K_{1}, K_{2}\right)$. We now consider two following cases:

Case 1. $\min \left\{\operatorname{diam}\left(K_{1}\right), \operatorname{diam}\left(K_{2}\right)\right\}=0$.

In this case, one of the sets $K_{1}$ or $K_{2}$ is singleton. Now, by the fact that $\left(K_{1}, K_{2}\right)$ is proximal and that $X$ is strictly convex, the other set must be singleton which is a contradiction.

Case 2. If $\min \left\{\operatorname{diam}\left(K_{1}\right), \operatorname{diam}\left(K_{2}\right)\right\}>0$.

Suppose that $T$ does not have a best proximity point. Let $\left(x^{*}, y^{*}\right) \in K_{1} \times K_{2}$ be such that $\left\|x^{*}-y^{*}\right\|=\operatorname{dist}(A, B)$. Since $T$ is cyclic relatively nonexpansive, we have

$$
\left\|T x^{*}-T y^{*}\right\| \leq\left\|x^{*}-y^{*}\right\|=\operatorname{dist}(A, B) .
$$

Thus, we must have $x^{*} \neq T y^{*}$ and $y^{*} \neq T x^{*}$. It now follows from the strictly convexity of $X$ that

$$
\left\|\frac{x^{*}+T y^{*}}{2}-\frac{y^{*}+T x^{*}}{2}\right\|=\operatorname{dist}(A, B) .
$$


Set $R:=\delta\left(K_{1}, K_{2}\right)$ and $r:=\min \left\{\left\|x^{*}-T y^{*}\right\|,\left\|y^{*}-T x^{*}\right\|\right\}$. Thus $r \in[0,2 R]$. Now, for all $v \in K_{2}$ we have

$$
\left\{\begin{array}{l}
\left\|x^{*}-v\right\| \leq R, \\
\left\|T y^{*}-v\right\| \leq R, \\
\left\|x^{*}-T y^{*}\right\| \geq r .
\end{array}\right.
$$

By the fact that $X$ is a uniformly convex Banach space, we conclude that

$$
\left\|\frac{x^{*}+T y^{*}}{2}-v\right\| \leq\left(1-\delta\left(\frac{r}{R}\right)\right) R, \quad \forall v \in K_{2},
$$

where, $\delta$ is a modulus of the convexity of $X$. Hence, $\delta_{\frac{x^{*}+T y^{*}}{2}}\left(K_{2}\right)<R$. Similarly, we can see that $\frac{\delta_{T x^{*}+y^{*}}}{2}\left(K_{1}\right)<R$. Therefore,

$$
\max \left\{\delta_{\frac{x^{*}+T y^{*}}{2}}\left(K_{2}\right), \delta_{\frac{T x^{*}+y^{*}}{2}}\left(K_{1}\right)\right\}<\delta\left(K_{1}, K_{2}\right) .
$$

Now, by an equivalent argument of the proof of Theorem 5, we get a contradiction.

Remark 1. We mention that the proof of Theorem 3.6 of [16] should be revised by a similar proof of Theorem 7 .

\section{REFERENCES}

[1] A. Abkar and M. Gabeleh, "Best proximity points for asymptotic cyclic contraction mappings," Nonlin. Anal., vol. 74, no. 18, pp. 7261-7268, 2011.

[2] A. Abkar and M. Gabeleh, "Global optimal solutions of noncyclic mappings in metric spaces," $J$. Optim. Theory Appl., vol. 153, no. 2, pp. 298-305, 2012.

[3] A. Abkar and M. Gabeleh, "Proximal quasi-normal structure and a best proximity point theorem," J. Nonlin. Convex Anal., vol. 44, no. 4, pp. 653-659, 2013.

[4] M. Al-Thagafi and N. Shahzad, "Convergence and existence results for best proximity points," Nonlin. Anal., vol. 70, no. 10, pp. 3665-3671, 2009.

[5] A. Amini Harandi, "Best proximity pair and coincidence point theorems for nonexpansive setvalued maps in Hilbert spaces," Bull. Iran. Math. Soc., vol. 37, pp. 229-234, 2011.

[6] A. Amini Harandi and A. Farajzadeh, "A best approximation theorem in hyperconvex metric spaces," Nonlin. Anal., vol. 70, no. 6, pp. 2453-2456, 2009.

[7] A. Amini Harandi, A. Farajzadeh, D. O'regan, and R. Agarwal, "Best proximity pairs for upper semicontinuous set valued maps in hyperconvex metric spaces," Fixed Point Theory Appl., vol. 2008, pp. 1-5, 2008.

[8] A. Amini Harandi, A. Farajzadeh, D. O'regan, and R. Agarwal, "Best proximity pairs theorems for continuous set valued maps," Fixed Point Theory Appl., vol. 2008, pp. 1-9, 2008.

[9] D. Brodskii, M.S.and Milman, "On the center of a convex set," Dokl. Akad. Nauk., vol. 59, pp. 837-840, 1948.

[10] C. Di Bari, T. Suzuki, and C. Vetro, "Best proximity points for cyclic Meir- Keeler contractions," Nonlin. Anal., vol. 69, no. 11, pp. 3790-3794, 2008.

[11] A. Eldred, W. Kirk, and P. Veeramani, "Proximal normal structure and relatively nonexpansive mappings," Studia Math., vol. 171, pp. 283-293, 2005.

[12] A. Eldred and P. Veeramani, "Existence and convergence of best proximity points," J. Math. Anal. Appl., vol. 323, no. 2, pp. 1001-1006, 2006. 
[13] R. Espínola, "A new approach to relativelt nonexpansive mappings," Proc. Amer. Math. Soc., vol. 136, no. 6, pp. 1987-1996, 2008.

[14] R. Espínola and A. Fernández-León, "On best proximity points in metric and Banach spaces," Canad. J. Math., vol. 63, pp. 533-550, 2011.

[15] A. Fernández-León, "Existence and uniqueness of best proximity points in geodesic metric spaces," Nonlin. Anal., vol. 73, no. 4, pp. 915-921, 2010.

[16] M. Gabeleh, "Semi-normal structure and best proximity pair results in convex metric spaces," Banach J. Math. Anal., vol. 8, no. 2, pp. 214-228, 2014.

[17] M. Gabeleh, "Minimal sets of noncyclic relatively nonexpansive mappings in convex metric spaces," Fixed Point Theory, to appear.

[18] M. Haddadi and H. Mazaheri, "Best approximation in vector spaces," Mat. Zametki, vol. 89, pp. 788-793, 2011.

[19] W. Kirk, "A fixed point theorem for mappings which do not increase distances," Amer. Math. Monthly, vol. 22, pp. 1004-1006, 1965.

[20] W. Kirk, S. Reich, and P. Veeramani, "Proximal retracts and best proximity pair theorems," Numer. Funct. Anal. Optim., vol. 24, pp. 851-862, 2003.

[21] P. Kumam, P. Salimi, and C. Vetro, "Best proximity point results for modified $\alpha$-proximal Ccontraction mappings," Fixed Point Theory Appl., vol. 2014:99, pp. 1-16, 2014.

[22] C. Mongkolkeha and P. Kumam, "Some common best proximity points for proximity commuting mappings," Optim. Lett., vol. 7, pp. 1825-1836, 2013.

[23] H. Nashine, C. Vetro, and P. Kumam, "Best proximity point theorems for rational proximal contractions," Fixed Point Theory Appl., vol. 2013:95, pp. 1-11, 2013.

[24] B. Pia̧tek, "On cyclic Meir-Keeler contractions in metric spaces," Nonlin. Anal., vol. 74, pp. 3540, 2011

[25] S. Sadiq Basha, "Extensions of Banach's contraction principle," Numer. Funct. Anal. Optim., vol. 31, pp. 569-576, 2010.

[26] S. Sadiq Basha and P. Veeramani, "Best proximity pair theorems for multifunctions with open fibres," J. Approx. Theory, vol. 103, pp. 119-129, 2000.

[27] V. Sankar Raj and P. Veeramani, "Best proximity pair theorems for relatively nonexpansive mappings," Applied General Topology, vol. 10, pp. 21-28, 2009.

[28] S. Shabani and A. Razani, "Global optimal solutions for noncyclic mappings in G-metric spaces," Miskolc Mathematical Notes, vol. 14, pp. 255-263, 2013.

[29] T. Suzuki, M. Kikkawa, and C. Vetro, "The existence of best proximity points in metric spaces with the property UC," Nonlin. Anal., vol. 71, pp. 2918-2926, 2009.

[30] W. Takahashi, "A convexity in metric space and nonexpansive mappings," Kodai Math. Sem. Rep., vol. 22, pp. 142-149, 1970.

[31] C. Vetro, "Best proximity points: convergence and existence theorems for p-cyclic mappings," Nonlin. Anal., vol. 73, pp. 2283-2291, 2010.

Author's address

Moosa Gabeleh

Department of Mathematics, Ayatollah Boroujerdi University, Boroujerd, Iran and School of Mathematics, Institute for Research in Fundamental Sciences (IPM), P.O. Box 19395-5746, Tehran, Iran

E-mail address: gab.mooegmail.com, Gabeleheabru.ac.ir 